\title{
MECHANISMS OF LIGHT ADAPTATION IN RAT RETINA
}

\author{
Daniel G. Green \\ Vision Research Laboratory, University of Michigan, Ann Arbor, MI 48109, U.S.A. \\ and \\ Maureen K. Powers \\ Department of Psychology, Vanderbilt University, Nashville, TN 37240, U.S.A.
}

(Received 7 July 1980; in revised form 7 August 1981)

\begin{abstract}
Green, Dowling, Siegel and Ripps (1975) J. gen. Physiol. 65, 483-502 found that both receptors and post-receptoral elements regulate the process of light adaptation in skate retina. As a test of the generality of this conclusion, we repeated their experiments on the retina of the intact albino rat. Increment threshold and intensity-response functions of aspartate-isolated receptor potentials, ERG $b$-waves and single retinal ganglion cell axons were measured, and all were found to be similar to those described by Green et al. (1975). In particular, the adaptive properties of the b-wave and ganglion cells were similar to each other, but different from those of the receptor potential. We conclude that the retinal mechanisms of light adaptation are similar in rat and skate.
\end{abstract}

\section{INTRODUCTION}

Until about ten years ago, the changes in sensitivity that occur during light adaptation were believed to originate somewhere beyond the photoreceptors. This belief was based on convincing evidence that adaptive effects can spread laterally across the retina; that is, illumination of one area of the retina can influence the sensitivity of areas that are not themselves illuminated (Lipetz, 1961; Rushton and Westheimer, 1962; Rushton, 1965; Cleland and Enroth-Cugell, 1968; Easter, 1968). These experiments demonstrated that the adaptive state of a given retinal area (subserved by one set of receptors) is dependent upon the adaptive state of a distant area (subserved by a different set of receptors), and most investigators concluded that the changes in sensitivity they observed must have resulted from a pooling of signals from many receptors. In the 1960's, when these experiments were published, it was assumed that each photoreceptor was an independent light detector. The possibility that any part of the pooling might occur within the photoreceptor layer itself therefore seemed remote. The most reasonable inference at the time was that all visual adaptation occurred proximal to the receptors.

Several observations during the 1970's caused this belief to be modified. First, recordings of the late receptor potential of the ERG showed that the presence of a steady background can desensitize primate cones (Boynton and Whitten, 1970). Second, recordings of the isolated receptor potential showed that skate rods (Dowling and Ripps, 1972), goldfish rods and cones (Witkovsky et al., 1973), frog rods and cones (Hood and Hock, 1973; Hood et al., 1973) and mudpuppy rods and cones (Normann and Werblin, 1974) display the full range of adaptive phenomena. Third, intracellular recordings from single photoreceptors showed that they can contribute substantially to the changes in sensitivity that occur in more proximal neurons (Grabowski et al., 1972; Baylor and Hodgkin, 1974; Werblin, 1974; Kleinschmidt and Dowling, 1975; Fain, 1976). All of these observations are inconsistent with the idea that adaptation does not occur in photoreceptors. We now know in addition that rods (and at least one class of cone) in cold-blooded vertebrate retinas are electrotonically coupled (Baylor et al., 1971; Fain, 1975; Schwartz, 1975; Copenhagen and Owen, 1976). This means that each photoreceptor is not an independent light detector, as had previously been assumed, and thus that the lateral spread of adaptation observed earlier could be due at least in part to pooling of signals within the photoreceptor layer. That is, adaptive signals might spread from one photoreceptor to another via interreceptor contacts. By the mid-70's, then, it was clear that some kind of visual adaptation must occur within the photoreceptors themselves.

In 1975, Green et al., reported results of experiments on skate retina that were designed to distinguish between receptoral and nonreceptoral components of adaptation. Their experiments showed that two principal mechanisms regulate visual sensitivity: one mediated by the photoreptors and the other by retinal components proximal to the photoreceptors. By examining the adaptive properties at different neuronal levels within the retina, they were able to establish the conditions under which each mechanism 
predominates in the control of overall retinal sensitivity. For example, they found that weak steady backgrounds can depress the sensitivity of b-wave and ganglion cell responses while having virtually no effect on the photoreceptors and horizontal cells. Under these conditions, the loss in sensitivity must be due to the influence of elements beyond the horizontal cells. With brighter adapting backgrounds, increment thresholds of receptors and more proximal elements increased in parallel. suggesting that under these conditions the receptors themselves govern sensitivity. Thus, in skate retina, the neural "network" regulates sensitivity at low levels of adaptation and the photoreceptors regulate sensitivity at high levels of adaptation.

It now seens clear that several adaptive mechanisms participate in the determination of retinal sensitivity, and that the mechanisms may differ for rod and cone systems (Hock and Hood, 1978). One unresolved question. however, is whether the mechanisms of adaptation in warm-blooded animals are fundamentally different from those in cold-blooded animals; the answer to this question is of considerable interest to those who study vision in animals as a model for vision in humans. In this paper, we present the results of experiments similar to those of Green et al. (1975) on an intact mammalian retina. Preliminary results were reported in Powers and Green (1978b).

\section{METHODS}

Subiects and surgical preparation

We used albino rats (Sprague-Dawley): 4 males $(280-440 \mathrm{~g}$ body $w t)$ and 12 females $(177 \cdot 310 \mathrm{~g})$ raised in our colony under dim red illumination. Each rat was placed in total darkness at least $15 \mathrm{hr}$ prior to surgery. and all surgical procedures were carried out in dim red illumination.

Animals from which optic tract units were to be recorded were anesthetized with urethane $11.5 \mathrm{~g} / \mathrm{kg}$ body wt, maximum dose). ERG's were recorded from rats that had received either urethane or Nembutal $(30 \mathrm{mg} \mathrm{kg}$ ). No difference in ERG's from these two groups could be detected.

Preparation for single unit experiments has been described before (Powers and Green. 1978a). A cannula was placed in the trachea, and another in the femoral vein: these animals were paralyzed during recording by constant infusion of a solution containing $10 \mathrm{mg} \mathrm{kg}$ per hr gallamine triethiodide (Flaxedil), $0.67 \mathrm{mg} / \mathrm{kg}$ per hr tubocurarine chloride. $30 \mathrm{mg} / \mathrm{kg}$ per hr urethane and $1.0 \mathrm{~cm}^{3} / \mathrm{kg}$ per hr $5^{\circ}$, dextrose in saline. Animals from which ERG's were to be recorded were not paralyzed. and hence had no cannulae inserted

For all experiments, the rat was placed in a rigid head holder (Baltimore Instruments sterotaxic device) on a rotatable platform. The pupil of the left (test) eye was dilated by topical application of $1_{0}^{\circ}$ atropine sulfate solution. and the lids retracted by applying slight tension to silk threads stitched to the upper and lower lid margins.

In most cases, different animals served as subjects in ERG and single unit experiments; however, we tried to record both b-wave and receptor potential in every ERG animal. If the eye appeared undamaged at the conclusion of the experiment and if the anesthetic had been Nembutal. the rat was allowed to recover and then used in a single unit experiment. Single unit experiments were always acute: if the physiological condition was satisfactory at the end of an experiment. we also recorded b-wave amplitudes.

\section{ERG h-Hate}

Our technique was conventional, and has been reported before (Green, 1973). A cotton wick electrode was placed on the cornea, in as peripheral a location as possible. The clectrode was soaked in rat Ringer's and the eye was irrigated frequently with Ringer's in order to maintain good electrical contact. A silver wire placed in one nostril served as the reference electrode. Signals were amplified (recording bandwidth $0.2-50 \mathrm{~Hz}$ ) and displayed on a storage oscilloscope. Figure 1A shows a sample ERG b-wave record.

\section{Receptor potential (PIII)}

Animals were prepared surgically as for b-waves, and we used the same electrodes, headholder. stimuli and electronics as for the b-wave. except that the recordings were d.c. coupled (bandwidth $0-50 \mathrm{~Hz}$ ).

The receptor potential was isolated from the influence of nonreceptoral elements by injecting small volumes (about $0.1 \mathrm{ml}$ ) of $100 \mathrm{mM}$ sodium aspartate Ringer into the eye. We had many technical failures; only the most successful procedure is described below.

The globe was punctured with a 30 ga. hypodermic needle in its ventral aspect, as far from the anterior surface as possible. Then, quickly, another $30 \mathrm{ga}$. hypodermic needle was inserted into the globe dorsally. We could visualize this penetration, and thus ensure that it was posterior to the lens and that the tip of the needle lay roughly central in the eye. Sometimes an exudate appeared at the ventral puncture site, and sometimes not. The degree to which the receptor potential was isolated did not seem to correlate with this occurrence.

This procedure resulted in complete suppression of the b-wave within a few minutes following the injection (see Fig. 1). Isolation usually remained complete for at least $30 \mathrm{~min}$, which was sufficient to finish the experimental series.

Examples of the receptor potentials we obtained are shown in Fig. 1. Note that the maximum amplitude exceeds that of the b-wave, and that the time to peak is longer than the b-wave. In addition, aspartate isolates a PIII which lacks a c-wave; in this regard its action resembles those of sodium azide and ischemia (Weidner, 1976). 
A

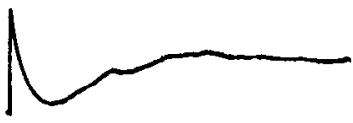

B

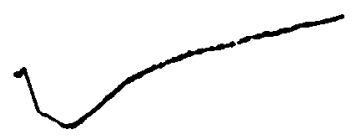

C

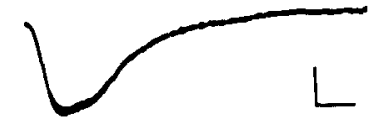

D

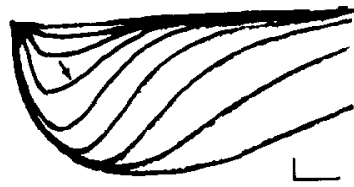

Fig, 1. (A) ERG of dark-reared albino rat. prior to aspartate injection. Note prominent c-wave. $I=-3.0 \log$ units from maximum. (B) 3 min following intraocular injection of $100 \mathrm{mM}$ sodium aspartate. A small upward inflection remains (probably from the b-wave), and the c-wave still appears. (C) $5 \mathrm{~min}$ following aspartate injection. The c-wave is completely absent, and only a hint of the b-wave remains. (D) Intensity series of aspartate-isolated receptor potential. beginning $6 \mathrm{~min}$ following injection and ending 30 min later. Bottom trace $I=-0.5 \log$ units from maximum (unfiltered xenon arc lamp). Successive traces are for intensity steps of $0.5 \mathrm{log}$ units, with the final (threshold) intensity at $-4.5 \log$ units below maximum. Arrow shows response at $-3.0 \log$ units, which is the same intensity used in $\mathbf{A}, \mathbf{B}$, and $\mathrm{C}$. This series was run in descending order of intensity. Calibration bars $0.5 \mathrm{sec}$ and $1.2 \mathrm{~V}$.

\section{Retinal ganglion cell axons}

The methodology has been described in detail before (Powers and Green, 1978a). Briefly, tungstenin-glass microelectrodes (Levick, 1972) were used to isolate action potentials from single retinal ganglion cell axons in the optic tract of paralyzed animals. These impulses were analyzed on-line by a laboratory computer system (Data General NOVA II). We used the same head-holder and stimuli as for the b-wave and receptor potential experiments. Units were defined as on- and off-center based upon their receptive field organization, determined by means of a small spot stimulus flashed on a tangent screen.

\section{Stimulus}

Stimulation was provided via a simple optical system. The source for the background light was a $108 \mathrm{~W}$ solid ribbon filament tungsten lamp (GE type 18A-T10-2P), and that for the test beam was a $150 \mathrm{~W}$ Osram xenon arc lamp. The unattenuated background was estimated to produce a flux of $6.0 \times 10^{4}$ quanta absorbed per sec in each rod and the unattenuated test $1.2 \times 10^{5}$ quanta per sec absorbed in each rod. The procedure used to estimate quantal absorption can be found in Green et al. (1977) or Cicerone and Green (1980). Throughout this paper, intensity is given in terms of the logarithmic attenuation of the light beam ( $I_{T}=$ test, $I_{B}=$ background) produced by neutral density filters.

A diffuser (1/2 ping-pong ball) was taped over the test eye; the other eye remained closed. The stimuli filled the diffuser completely, and test and background were spatially coincident. Broad-band "white" light was used for all experiments reported here, with the exception of those in Fig 7, where we used monochromatic test flashes (produced by interference filters). Test flash duration was $200 \mathrm{msec}$. Ample time was allowed for dark adaptation between flashes of higher intensities and for light adaptation to newly introduced backgrounds before determining the response to a test flash (Green, 1973).

\section{Measurement of the response}

Absolute and incremental thresholds were determined for all three responses (b-wave, receptor potential and ganglion cells). We arbitrarily defined threshold for b-wave and receptor potentials as a $50 \mu \mathrm{V}$ change in potential during stimulus presentation. This difference was largely dictated by the level of noise in the electronics. Threshold for ganglion cell fibers was defined as one extra spikc per test stimulus presentation, averaged over 10 presentations. We made such judgments from computer-generated poststimulus time histograms that were produced on-line during the experiments ( $c f$. Powers and Green, 1978a; Cicerone and Green, 1980).

The amplitude of each response to test stimuli of varying intensities was also recorded. For the b-wave and the isolated receptor potential, peak amplitude was measured relative to baseline values before presentation of the test flash. For ganglion cell axons, the number of spikes during stimulus presentation was measured relative to the average ongoing firing rate before presentation of the test flash. These measurements were then used to construct intensity response (IR) functions. For each animal we measured IR functions for test flashes presented under three different conditions: (1) with no background, (2) with a background that increased $b$-wave threshold by about $1 \log$ unit $(\log I=-3.8)$, and (3) with a background that increased $b$-wave threshold by about $2 \log$ units $(\log I=-2.8)$.

Each test flash was presented consecutively 4-6 times for both threshold and IR determinations; values reported here are means.

\section{RESULTS}

\section{ERG}

The b-wave of the ERG was similar in form to previous reports (Dowling, 1967; Green, 1971, 1973), as was the aspartate-isolated receptor potential (Green, 1973; Green and Dowling. 1975). (See Fig. 1.) 


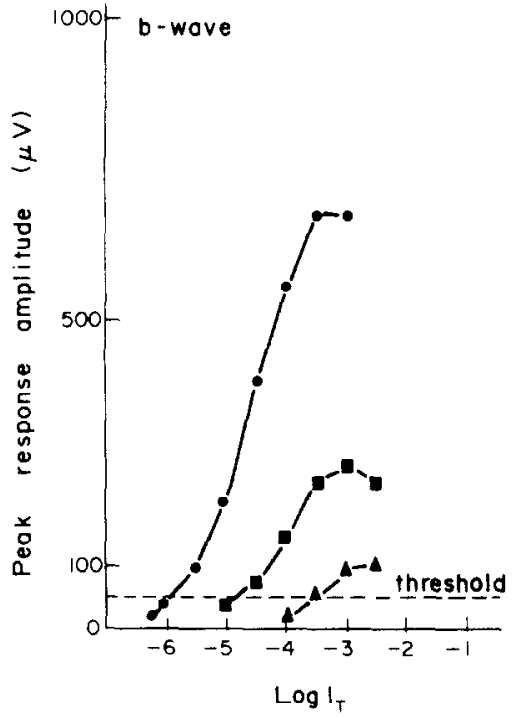

Fig. 2. Intensity vs response functions for the b-wave. Data from one animal. tested under three background conditions. Each point is the average amplitude of 4-6 presentations of the stimulus. Circles: no background present. Squares: background selected to reduce b-wave absolute sensitivity by approximately $1 \log$ unit $(\log I=-3.8)$. Triangles: background selected to reduce b-wave absolute sensitivity by $2 \log$ units $(\log I=-2.8)$.

Contrary to previous reports (Dodt and Echte. 1961: Weidner. 1976). however, a c-wave was present in the ERG of every animal we tested. Evidence has since been obtained that c-waves are absent in albino rats reared in ordinary colony conditions (with cyclic fluorescent lighting), but present in albinos reared in dim red light; that evidence is summarized elsewhere (Graves et al. 1979: Graves and Green. 1980).

Figure 2 shows a representative intensity vs response function for the b-wave for one animal. With no background (circles). threshold response was obtained when the test was $6 \log$ units dimmer than maximum. Higher intensities produced larger b-waves. but at about $2.5 \mathrm{log}$ units above threshold the response grew no farther.

Intensity-response functions for test flashes superimposed on backgrounds that reduced b-wave threshold by 1 (squares) or 2 (triangles) log units had reduced maximum amplitudes: the baseline potential also shifted upon presentation of these backgrounds.

\section{Receptor potential}

Figure 3 shows intensity-response functions for the isolated receptor potential from the same animal as in Fig. 2. With no background present (circles). threshold response was obtained when the test flash was about $4.3 \mathrm{log}$ units dimmer than maximum. Thus. absolute threshold for the receptor potential was about $1.7 \mathrm{log}$ units higher than for the b-wave.

When we imposed a background that increased b-wave threshold by one log unit. threshold for the receptor potential remained unchanged (squares in Fig. 3). A background that increased b-wave threshold by 2 log units (triangles) had a much smaller effect on the receptor potential: it shifted threshold by only a factor of 3 . The dimmer background did not reduce maximum response amplitude. but the brighter background did (see also Fig. 6a). In addition. the brighter background produced a shift of the intensity-response function toward higher intensities, although the shift was smaller for the receptor potential than for the $b$-wave under the same conditions.

\section{Optic tract fihers}

Figures 4 and 5 show sample intensity-response functions from retinal ganglion cell axons. It is readily apparent that absolute threshold (circles) was lower than for either the b-wave or receptor potential. In general, the ganglion cells from which we recorded were $1 \log$ unit more sensitive than b-waves. a finding that was confirmed when b-wave and ganglion cell data were obtained from the same animal. Ganglion cells were generally about $2.5 \log$ units more sensitive than the receptor potential.

The effect of background illumination on ganglion cell response was similar to the effect on b-wave response, in the sense that the entire curve was shifted to the right when a background was added. However, the shift was larger in ganglion cells for a given background, and there was no apparent reduction in the maximum spike discharge when a background was imposed.

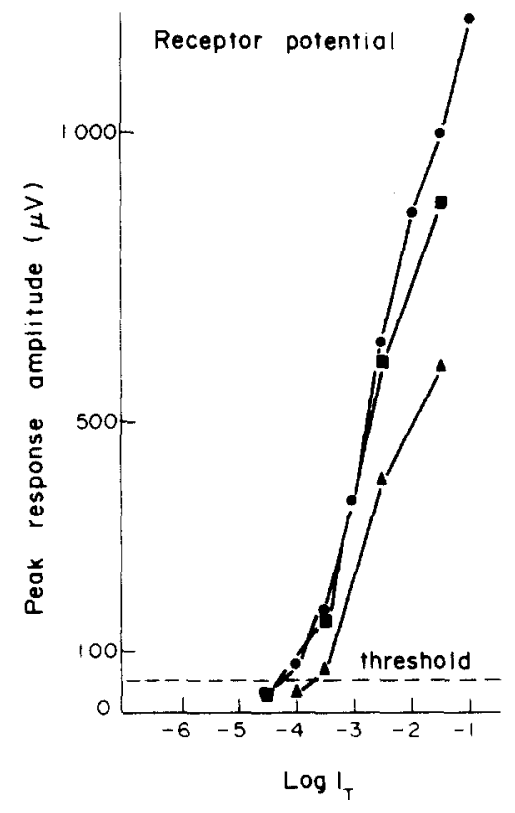

Fig. 3. Intensity vs response functions for the isolated receptor potential from the same animal as in Fig. 2. Each point represents mean amplitude over 4-6 stimulus presentations. Symbols as in Fig. 2. 


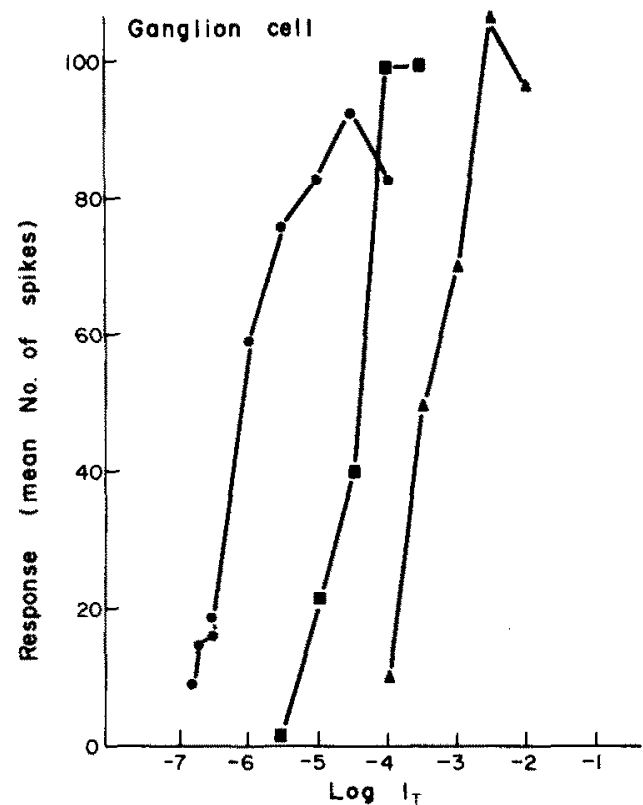

Fig. 4. Intensity vs response functions for a single retinal ganglion cell axon (off-center). Each point represents the mean number of spikes above baseline in 10 presentations of the same stimulus. Symbols as in Fig. 2.

We recorded similar functions from 14 additional units in optic tract. No difference was observed between on- and off-center units.

\section{Comparison across retinal levels}

Figure 6 shows mean intensity-response functions for 4 receptor potential experiments (top panel), 5 b-wave experiments (middle panel) and a single representative ganglion cell experiment (bottom panel). All responses have been scaled in order to facilitate comparison among the three categories of response.

Several relations are apparent. First, with no background present (circles), the intensity-response functions are similar in form for all three response types. Each is essentially sigmoid, and shows evidence of saturation at the higher intensities. In fact, if they were shifted horizontally, in the absence of any background illumination, the three curves would superimpose quite well.

The differences in absolute sensitivity are illustrated in this figure as well. Note that in order to superimpose the lower portion of the intensity-response functions (circles) at $I=-4$, one would have to shift the b-wave function rightward by nearly $2 \log$ units, and the ganglion cell function by nearly $3 \log$ units.

Backgrounds of the intensities we used clearly had more influence upon b-wave and ganglion cell responses than upon the receptor potential (squares and triangles in Fig. 6). Furthermore, the b-wave and ganglion cell responses were not altered in the same way when the test was superimposed on a background field; b-wave maximum amplitude was con- sistently decreased, whereas maximum ganglion cell spike output was not.

Figure 7 shows incremental thresholds for mid- and long-wavelength test stimuli on white backgrounds for all three response types. The placement of the curves on the ordinate has been adjusted so that (1) absolute thresholds of a given response type coincide for both test wavelengths, (2) absolute thresholds for receptor potential and b-wave coincide, and (3) the lower portion of the b-wave and ganglion cell curves coincide.

As in the skate (see Fig. 4 in Green et al.. 1975), the increment threshold curves for the $h$-wave and ganglion cells superimpose, and both lie to the left of the receptor potential curve. But in contrast to the skate. the increment threshold curves from the rat reflect the influence of more than one class of photoreceptor. Note that both $b$-wave and ganglion cell curves diverge as a function of test wavelength at high $I_{B}$, and that the slope of the receptor potential curve differs from that of the two proximal responses at low $I_{B}$. These differences are almost certainly due to the presence of photopic receptors in the rat (Green, 1971. 1973), which are absent in skate (Dowling and Ripps, 1970).

The backgrounds used in generating the intensityresponse functions in previous figures (Figs 2-6) were -3.8 and $-2.8 \log$ units on the abscissa of Fig. 7. Comparing the increment thresholds upon those backgrounds with the intensity-response functions in Fig. 6 demonstrates that there were no observable changes in response amplitude of the receptor potential until the intensity of the background was sufficient to cause an inflection in the increment threshold curve for the receptor potential. That is, a

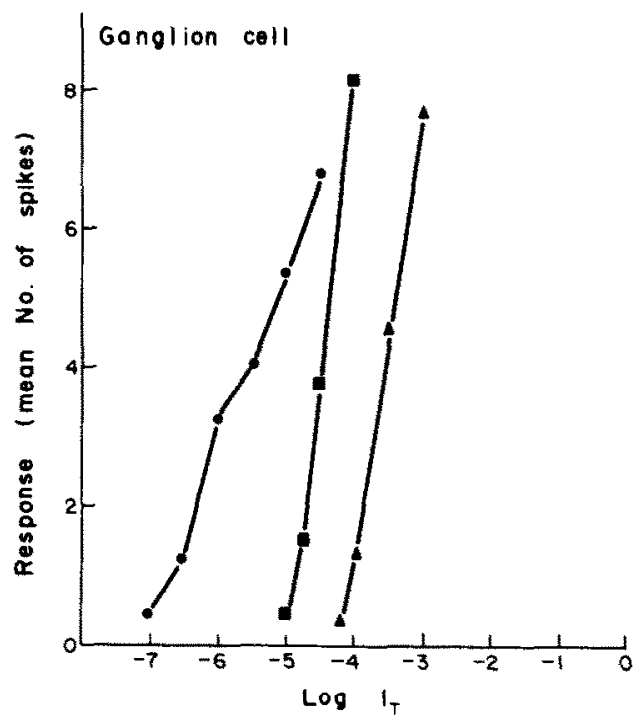

Fig. 5. Intensity vs response functions for a second ganglion cell fiber from the same animal as in Fig. 4. This was also an off-center unit. Symbols as in Fig. 2. Note the difference in scale on the ordinate between Figs 4 and 5 . 


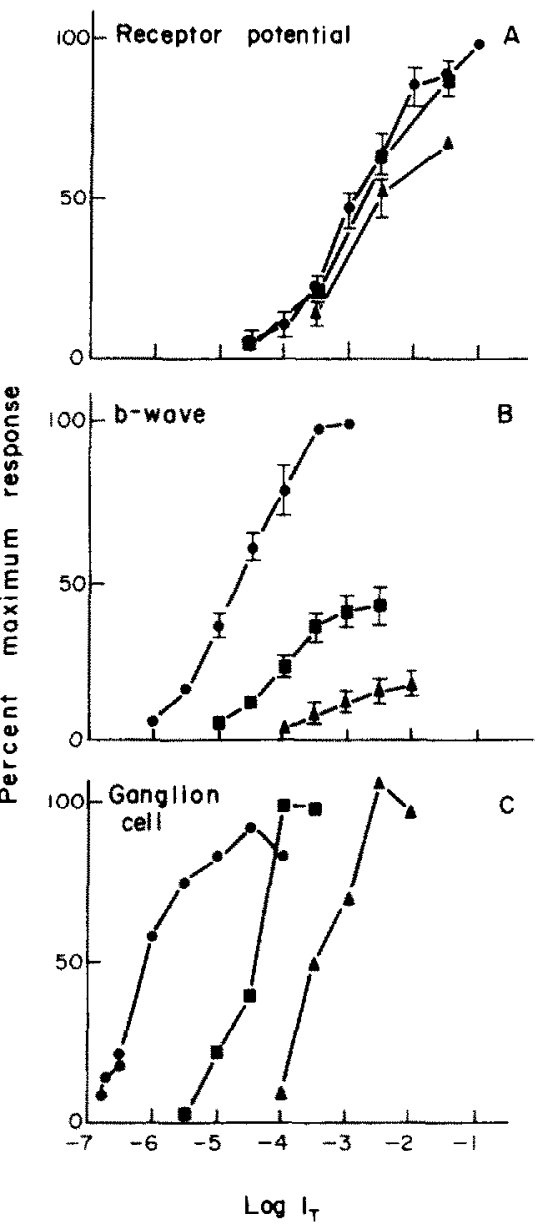

Fig. 6. Comparison of intensity vs response functions across levels of retinal processing. (A) Mean response amplitudes for receptor potential experiments from 4 preparations. (B) Mean response amplitudes for b-wave experiments from 5 preparations. (C) Intensity vs response function from the ganglion cell experiment shown in Fig. 4. All values have been scaled to show percent maximum response, to facilitate comparison. Bars \pm 1 SEM; symbols as in Fig. 2.

background of $-3.8 \log$ units (which strongly desensitized the proximal elements) affected neither the increment threshold nor the intensity-response function of the receptor potential, while a background one log unit brighter $(-2.8)$ affected both.

\section{DISCUSSION}

This is the first direct comparison of light adaptation at three different levels of retinal processing in a mammalian retina. Dowling (1967), whose results are similar to ours for the $b$-wave and receptor potential, did not report on ganglion cell activity from rat retina. Dowling used two techniques for recording receptoral responses. He measured the a-wave of the ordinary ERG, and he also measured the receptor potential from eyes in which the retinal circulation was impeded. The aspartate-infusion technique we used in the present series of experiments gave results that resemble Dowling's.

The experiments reported here show that dim backgrounds can significantly alter the sensitivity of postreceptor elements in mammalian retina in riv without affecting the sensitivity of the receptors themselves. The validity of this conclusion rests on the assumption that the aspartate-isolated potential is a reasonable indicator of receptor activity. Is that assumption warranted in the case of our experiments? The retina was certainly in poorer physiological condition following exposure to aspartate: in particular. the disappearance of the c-wave in our recordings may indicate that we did more than simply "isolate receptors". Moreover, the large, slow isolated potentials we measured were probably conlaminated by contributions from slow PIII (Faber, 1969). It has been suggested. however. that slow PIII arises from Müller cells in response to the light-induced decrease in potassium concentration in the region of the photoreceptor outer segments (Witkovsky et al., 1975: Oakley and Green. 1976). Recent experiments on rabbits lend support to this notion for mammalian retina (Lurie and Marmor, 1980). Because it is the photoreceptor responses that provide the driving force underlying the potassium changes (Oakley ot $a$.. 1979) and presumably slow PIII as well, the characteristics of the aspartate-isolated potential we measured are surely at least correlated with the characteristics of the photoreceptors, and hence they are a reasonable indication of the adaptive state of the photoreceptors. As far as the present experiments are concerned. it matters not in determining whether receptors are adapted whether one measures the receptor potential or its correlates. The point remains the same: dim backgrounds can significantly alter the sensitivity of postreceptor elements without affecting the receptors themselves.

Figure 6 of this paper is similar to Fig. 3 in Green et al. (1975), which compares intensity-response functions for the receptor potential, S-potential and $\mathrm{b}$-wave of the skate retina. Our results for the receptor potential and b-wave (Fig. 6A and B) are virtually identical to theirs; a background that shifted the b-wave curve $1 \log$ unit to the right and decreased its amplitude had no effect on the receptor potential. When Green et al. (1975) tested brighter backgrounds, they found that a background that shifted the b-wave curve $2 \log$ units did have an adapting effect on the receptor potential. We find the same is true in the rat. Figure $6 \mathrm{~A}$ shows that the brighter background results in (a) further depression of the b-wave maximum amplitude and (b) a small shift to the right and slight depression of maximum amplitude of the receptor potential.

Our results thus confirm those of Green et al. (1975), and extend them to a mammalian retina. Like Green et al. (1975), we find that the adaptive properties of the b-wave and ganglion cells are similar to one another, but different from the adaptive proper- 


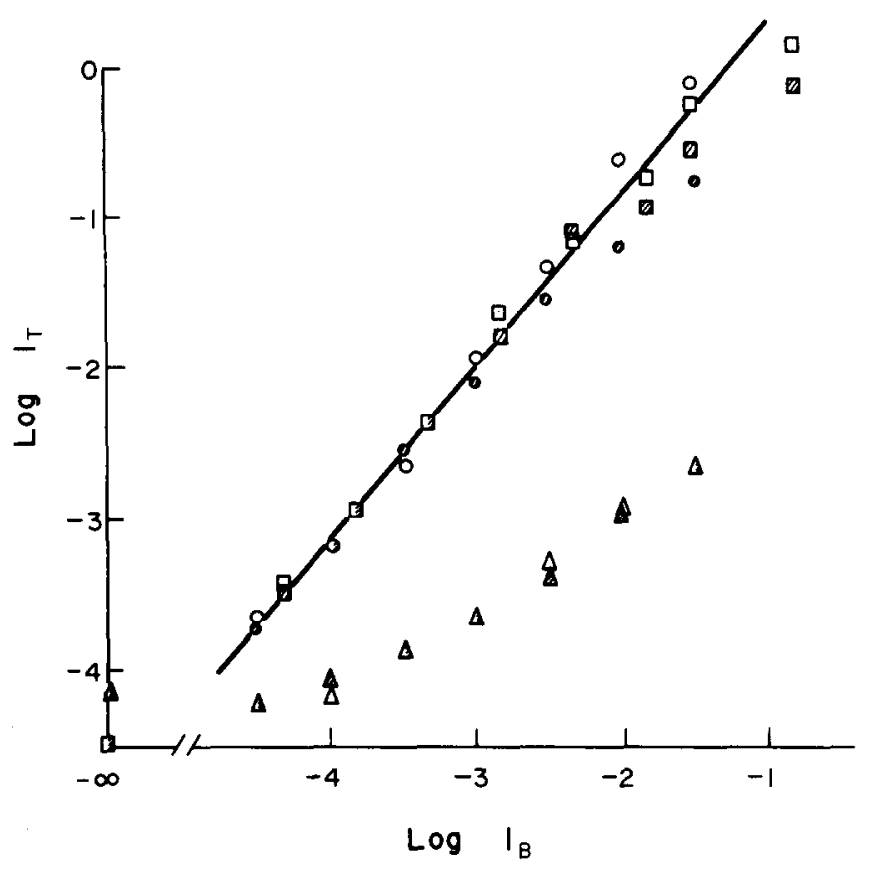

Fig. 7. Increment threshold functions for a ganglion cell (squares). for the b-wave (circles) and for the receptor potential (triangles). Open symbols: $500 \mathrm{~nm}$ test. Closed symbols: $625 \mathrm{~nm}$ test for b-wave and receptor potential and $600 \mathrm{~nm}$ for ganglion cell. Background tungsten white, as in other figures. B-wave and receptor potential were recorded from the same animal (though different from the one shown in Figs 2 and 3 ).

ties of the receptors. We also find, as they did, that the absolute threshold differs across retinal elements, and that the receptors appear to be less sensitive than the more proximal elements. One must keep in mind, however, that the response we attribute to the receptors is a massed response that originates in many receptors and is recorded at the cornea. Such a signal may be significantly attenuated relative to one that might be recorded from each receptor directly.

As in the skate, the loss of sensitivity in the rat retina at low levels of illumination must be due to a process of "network" adaptation, originating proximal to the receptors, because the receptor response itself exhibits little change in sensitivity. The loss of sensitivity at higher levels of illumination is not as easy to interpret, however. In skate retina, the rods continue to govern light adaptation with bright backgrounds. But in rat retina, cone mechanisms intrude when bright backgrounds are used (Green, 1971, 1973). Thus in rat, we are able to compare the adaptive properties of rod photoreceptors with those of the b-wave and ganglion cells only at lower levels of illumination.

The results of the experiments reported here show that the mechanisms of light adaptation to dim backgrounds in the albino rat retina are similar to those in the skate retina. It seems likely, although we have not tested the hypothesis, that the mechanisms of dark adaptation would also be similar in skate and rat. In fact, the experiments of Ernst and Kemp (1972) show clearly that a further stage of dark adaptation exists after the processes in the rat retina that give rise to PIII. Examination of these mechanisms in other species must be made before we can conclude that there are universal principles of light or dark adaptation for all vertebrates.

Acknowledgements - Supported by EY00379 from the U.S. Public Health Service to D.G.G. We thank A. Graves and C. Brown for participating in these experiments. M.K.P. was supported by EY07031 (D. Y. Teller, P.I.) and EY03352 during preparation of the manuscript.

\section{REFERENCES}

Baylor D. A., Fuortes M. G. F. and O'Bryan P. M. (1971) Receptive fields of cones in the retina of the turtle. $J$. Physiol. 214, 265-294.

Baylor D. A. and Hodgkin A. L. (1974) Changes in time scale and sensitivity in turtle photoreceptors. $J$. Phisiol. 242. 729-758.

Boynton R. M. and Whitten D. N. (1970) Visual adaptation in monkey cones: recordings of late receptor potentials. Science 170, 1423-1426.

Cicerone C. M. and Green D. G. (1980) Dark adaptation within the receptive field centre of rat retinal ganglion cells. J. Physiol. 301, 535-548.

Cleland B. G. and Enroth-Cugell C. (1968) Quantitative aspects of sensitivity and summation in the cat retina. J. Physiol. 198, 17-38.

Copenhagen D. R. and Owen W. G. (1976) Functional characteristics of lateral interactions between rods in the retina of the snapping turtle. J. Physiol. 259, 251-282.

Dodt E. and Echte K. (1961) Dark and light adaptation in pigmented and white rat as measured by electroretinogram threshold. $J$. Neurophysiol, 24, 427-445. 
Dowling J. E. (1967) The site of visual adaptation. Science 155, $273-279$.

Dowling J. E. and Ripps H. (1970) Visual adaptation in the retina of the skate. J. gen. Physiol. 56, 491-520.

Dowling J. E. and Ripps H. (1972) Adaptation in skate photoreceptors. J. gen. Physiol. 60. 698-719.

Easter S. S. (1968) Adaptation in the goldfish retina. $J$. Physiol. 195, 273-281.

Ernst W. and Kemp C. M. (1972) The effects of rhodopsin decomposition on PIII responses of isolated rat retinae. Vision Res. 12, 1937-1946.

Faber D. S. (1969) Analysis of the slow transretinal potentials in response to light. Ph.D. Thesis, State University of New York at Buffalo.

Fain G. L. (1975) Quantum sensitivity of rods in the toad retina. Science 187,833841 .

Fain G. L. (1976) Sensitivity of toad rods: dependence on wave length and background illumination. $J$. Physiol. 261, 71-101.

Grabowski S. R., Pinto L. H. and Pak W. L. (1972) Adaptation in retinal rods of axolotl: intracellular recordings. Science 176, 1240-1242.

Graves A. L. and Green D. G. (1980) Light exposure can selectively abolish the c-wave of the albino rat ERG. Invest. Ophthal. visual Sci, Suppl. 19, 39.

Graves A. L. Green D. G. and Powers M. K. (1979) The $\mathrm{c}$-wave of the electroretinogram in light and dark-reared albino rats. Neurosci. Abstr. 5, 786 .

Green D. G. (1971) Light adaptation in the rat retina: Evidence for two receptor mechanisms. Science 174, 598600.

Green D. G. (1973) Scotopic and photopic components of the rat electroretinogram. $J$. Physiol. 228, 791-797.

Green D. G. and Dowling J. E. (1975) Electrophysiological evidence for rod-like receptors in the gray squirrel, ground squirtel, and prairie dog retinas. $J$. comp. Nourol. 159. 461-472.

Green D. G., Dowling J. E., Siegel I. M. and Ripps H. (1975) Retinal mechanisms of visual adaptation in the skate. J. gen. Physiol. 65, 483-502.

Green D. G.. Tong L. and Cicerone C. M. (1977) Lateral spread of light adaptation in the rat retina. Vision Res. $17,479-486$.

Hock P. A. and Hood D. C. (1978) Light adaptation of the frog's 580 cone system: a comparison of receptor and ganglion cell sensitivity changes. Vision Res. 18 , $1155-1164$.

Hood D. C. and Hock P. A. (1973) Recovery of cone recep- tor activity in the frog's isolated retina. Vision Res. 13, 1943 1951 .

Hood D. C. Hock P. A. and Grover B. G. (1973) Dark adaptation in the frogs rods. Vision Res. 13, 19521963.

Kleinschmidt J. and Dowling J. E. (1975) Intracellular recording from gecko photoreceptors during light and dark adaptation. J gen. Phisiol. 66, 617 648.

Levick W. R. (1972) Another tungsten microelectrode. Med biol. Engng. 10, 510 515 .

Lipetz L. E. (1961) A mechanism of light adaptation Srienci 133, 639640 .

Lurie M. and Marmor M. F. (1980) Similarities between the c-wave and slow PIII in the rabbit eye, hotest. Ophthal. visual Sci. 19. $1113 \cdot 1116$.

Normann R. A. and Werblin F. S. (1974) Light and dark adaptation of vertebrate rod and cone responses. I. gen. Physiol. 63, 37. 61.

Oakley B., Flaming D. G, and Brown K. T. (1979) Effects of the rod receptor potential upon retinal extracellular potassium concentration. $J$ gen. Physiol. 74. 713.737.

Oakley B. and Green D. G. (1976) Correlation of lightinduced changes in retinal extracellular potassium con* centration with c-wave of the electroretinogram. $J$. Neurophysiol. 39, 1117 1133 .

Powers M. K. and Green D. G. (1978a) Single retinal ganglion cell responses in the dark-reared rat: grating acuity. contrast sensitivity, and defocusing. Vision Res. 18, 1533-1539.

Powers M. K. and Green D. G. (1978b) Retinal mechanisms of light adaptation in the albino rat. Neurosci. Abstr. 4, 641

Rushton W. A. H. (1965) Bleached rhodopsin and visual adaptation. J. Physiol. 181, 645655

Rushton W. A. H. and Westheimer $G$. (1962) The effect upon the rod threshold of bleaching neighbouring cods. J. Physiol. 164, 318-329.

Schwartz E. A. (1975) Cones excite rods in the retina of the turtle. J. Phisiol. 246, 639.651.

Weidner $C$. (1976) The c-wave in the erg of alhino rat Vision Res. 16, 753-763.

Werblin F. S. (1974) Control of retinal sensitivity 11 Lateral interactions at the outer plexiform layer. I. gen. Physiol. 63, 62-87.

Witkovsky P.. Nelson J. and Ripps H. (1973) Action spectra and adaptation properties of carp photoreceptors. $J$. gen. Physiol. 61, 401-423.

Witkorsky P.. Dudek F. E. and Ripps H. (1975) Slow PIII component of the carp electroretinogram. J. gen. Physiol. 65. $119 \cdot 134$

Note added in proof Our conclusions relate to rod-dominated visual systems. For a recent application of similar techniques to cone systems, see Dawis S. M. and Purple R. L. (1981) Vision Res. 21, 1169-1180. 